Tropical Journal of Pharmaceutical Research January 2018; 17 (1): 29-34

ISSN: $1596-5996$ (print); 1596-9827 (electronic)

(C) Pharmacotherapy Group, Faculty of Pharmacy, University of Benin, Benin City, 300001 Nigeria.

\title{
Regulation of MicroRNA-378 expression in mature human adipose tissue cells by adiponectin, free fatty acids and dexamethasone
}

\author{
Lulian Xu, Li Jiang, Kefeng Gu, Zhenzhen Liu, Xu Xu* \\ Department of Pediatric Endocrinology, Wuxi Children's Hospital, No. 299 Qingyang Street, Wuxi, China.
}

${ }^{*}$ For correspondence: Email: jg9048@163.com

Sent for review: 11 July 2017

Revised accepted: 20 October 2017

\begin{abstract}
Purpose: To investigate the effects of adiponectin (ADPN), free fatty acids (FFAs), growth hormone $(G H)$, and dexamethasone (DEX) on miR-378 expression in human adipose tissue cells, and their influence on regulation of obesity and insensitivity to insulin.

Methods: Human pre-adipocytes were cultured and differentiated. Adipocytes were treated with ADPN, FFAs, GH and DEX. RNA was isolated and quantified by real-time polymerase chain reaction (RTPCR).

Results: Stimulation with FFA led to significant up-regulation of the expression of MiR-378 (approximately 3.8-fold) relative to control at the 4th hour $(p<0.01)$ in human mature adipose tissue cells. The expression of MiR-378 was increased almost 1.5-fold by ADPN within $24 \mathrm{~h}$, relative to untreated control $(p<0.05)$.

Conclusion: The results of this study demonstrate that miR-378 expression is influenced by FFAs, $A D P N$, and DEX, the interaction of which may be involved in the pathogenesis of obesity-induced insensitivity to insulin. Thus, miR-378 is a potential biomarker for predicting the risk of complications, especially insulin resistance in obesity
\end{abstract}

Keywords: MiR-378, Adipocytes, Adiponectin, Free fatty acids, Growth hormone, Dexamethasone, Obesity, Insulin resistance

\footnotetext{
This is an Open Access article that uses a funding model which does not charge readers or their institutions for access and distributed under the terms of the Creative Commons Attribution License (http://creativecommons.org/licenses/by/4.0) and the Budapest Open Access Initiative (http://www.budapestopenaccessinitiative.org/read), which permit unrestricted use, distribution, and reproduction in any medium, provided the original work is properly credited.

Tropical Journal of Pharmaceutical Research is indexed by Science Citation Index (SciSearch), Scopus, International Pharmaceutical Abstract, Chemical Abstracts, Embase, Index Copernicus, EBSCO, African Index Medicus, JournalSeek, Journal Citation Reports/Science Edition, Directory of Open Access Journals (DOAJ), African Journal Online, Bioline International, Open-J-Gate and Pharmacy Abstracts
}

\section{INTRODUCTION}

The typical feature of obesity is body fat in excess of what is normal, arising from imbalance between energy intake and energy expenditure [1]. Childhood and adult obesity are two of the most critical threats to health in recent decades $[2,3]$. Obesity is caused by several factors, and its pathogenesis involves interplay of social, genetic and environmental considerations [4]. A plethora of evidence point to the important roles of genetic factors in the etiology of obesity. It has been reported that ADPN delays and suppresses diabetes-associated metabolic derangements [5]. It was recently demonstrated that the adipose tissue of obese individuals contains excess levels of FFAs, a situation considered important in obesity and insulin resistance [6]. However, 
the bases of the influences of ADPN, FFAs, GH and DEX on insulin sensitivity and obesity remain unclear.

MicroRNAs (miRNAs) are small (19 22 nucleotides), double-stranded RNAs that repress translation and/or destabilize mRNA [7]. One of these miRNAs, miR-378 is involved in the regulation of lipid metabolism $[8,9]$. In this study, the effects of ADPN, FFAs, GH and DEX on miR378 expression in mature adipocytes were investigated with a view to unraveling the influence of miR-378 on the etiology of insulin insensitivity.

\section{EXPERIMENTAL}

\section{Human pre-adipocytes culture and differentiation}

Human pre-adipocytes (ScienCell Research Laboratories) were cultured in Pre-adipocyte Medium (PAM; ScienCell Research Laboratories) containing $5 \%$ fetal bovine serum (FBS), $1 \%$ pre-adipocyte growth supplement (PAGS), and 1 $\%$ streptomycin/penicillin solution $(\mathrm{S} / \mathrm{P})$ at $37{ }^{\circ} \mathrm{C}$ in a humidified atmosphere with $5 \% \mathrm{CO}_{2}$. For induction of differentiation, confluent cells (day 0 ) were maintained in serum-free PAM (SF-PAM) to which 100nM DEX, $50 \mathrm{nM}$ insulin, $100 \mu \mathrm{M}$ rosiglitazone and $0.5 \mathrm{mM}$ 3-isobutyl-1methylxanthine were added. The culture medium was replaced twice within four days at 48hintervals. Subsequently, it was replaced with SFPAM to which $50 \mathrm{nM}$ insulin was added. The medium was renewed every $48 \mathrm{~h}$ until the appearance of fat droplets on the $15^{\text {th }}$ day. Lipid production was measured by Oil Red O staining.

\section{Treatment with ADPN, FFAs, GH and DEX}

On day 15 following differentiation, the mature human adipocytes were incubated overnight in SF-PAM and thereafter treated with $3 \mathrm{ug} / \mathrm{mL}$ ADPN (Abcam), $1 \mathrm{mmol} / \mathrm{L}$ FFA mixture containing lauric, myristic, oleic, linoleic and arachidonic acids (Sigma); $10 \mathrm{ng} / \mathrm{mL} \mathrm{GH}$ (Sigma) and $1 \mathrm{mM}$ DEX (Biosharp). Three durations of exposure were used i.e. $4 \mathrm{~h}, 8 \mathrm{~h}$ and $24 \mathrm{~h}$. After each period of exposure, the cells were harvested and used for further investigations $[10,11]$.

\section{RNA extraction and quantitation with RT-PCR}

The extraction of total RNA was carried out with TRIzol reagent (Invitrogen). The amount of extracted RNA was determined spectrophotometrically using One Drop Spectrophotometer (Qite) with appropriate standards. Relative fold-increases in expressions were computed using comparative CT procedure. Total RNA (200ng) was used to synthesize complementary DNA (cDNA) using TaqMan microRNA Reverse Transcriptase Kit (ABI) according to manufacturer's protocol. Applied Biosystems 7500 Sequence Detection System was used for Real-time RT-PCR as specified in the manufacturer's manual. Initial denaturation was effected by incubation of samples at $95{ }^{\circ} \mathrm{C}$ for $10 \mathrm{~min}$, and thereafter with 40 cycles of PCR for $15 \mathrm{sec}$ at $95^{\circ} \mathrm{C}$, and for 60 $\mathrm{sec}$ at $60^{\circ} \mathrm{C}$. All reactions were carried out in triplicate. Relative expressions were calculated by $2^{\Delta \Delta C t}$ procedure [12].

\section{Statistical analysis}

One-way analysis of variance (ANOVA) was used for data analysis with version 16 of SPSS. The results are expressed as mean \pm SE. Values of $p<0.05$ were taken as indicative of statistically significant difference.

\section{RESULTS}

\section{Effect of ADPN on expression of miR-378}

Figure 1 shows the differentiation of human preadipocytes into mature adipocytes. The results on Figure 2 show the effect of $3 \mathrm{ug} / \mathrm{mL}$ ADPN treatment at 4,8 and $24 \mathrm{~h}$ on expression of miR378,15 days post-differentiation. Exposure to ADPN provoked time-determined increases in miR-378 expression, which continued up to $24 \mathrm{~h}$. At $24 \mathrm{~h}$, the expression of miR-378 in the ADPNtreated adipocytes was almost 0.5 -fold higher than in the control $(p<0.05$, Figure $2 A)$.

\section{Effect of FFAs on expression of miR-378}

The effect of FFAs on miR-378 expression in cultured human adipocytes was analyzed using qPCR treatment. The adipose tissue cells were exposed in culture to $1 \mathrm{mM}$ FFA cocktail. The results on Figure $3 \mathrm{~A}$ indicate that miR-378 expression at $4 \mathrm{~h}$ was up-regulated almost 3.8fold relative to the control group by FFA ( $p<$ 0.01 ). The up-regulation continued up to $8 \mathrm{~h}$ and subsequently, the expression began to decrease, although it still showed statistical significance up to $24 \mathrm{~h}$.

\section{Effects of GH on expression of miR-378 in mature human adipose tissue cells}

There were no significant differences in miR-378 expression between $\mathrm{GH}$-treated and untreated groups (Figure 4). 


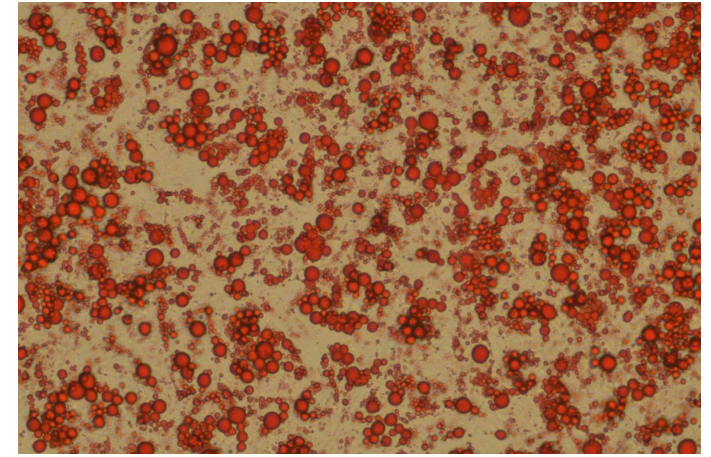

Figure 1: Micrograph of differentiated human preadipocytes (day 15), showing fat droplets. (Oil Red O stain)

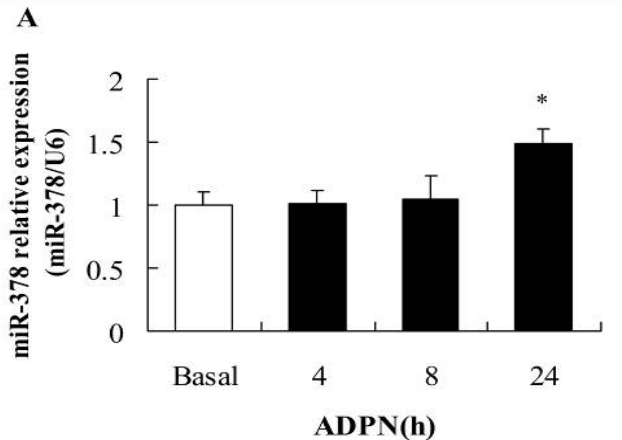

\section{Effect of DEX on expression of miR-378 in mature human adipose tissue cells}

The expression of miR-378 was increased almost 1.5 folds after $24 \mathrm{~h}$ by $1 \mathrm{mM}$ DEX, relative to control $(p<0.05$, Fig. 5A).

\section{MiR-103 as an endogenous control}

The stable microRNA transcript, miR-103 was employed as internal control for verifying the results obtained in miR-378 studies. There were similarities in the results obtained (Figures $2 \mathrm{~B}$, Figure $3 \mathrm{~B}$, Figure $4 \mathrm{~B}$ and Figure $5 \mathrm{~B}$ ).

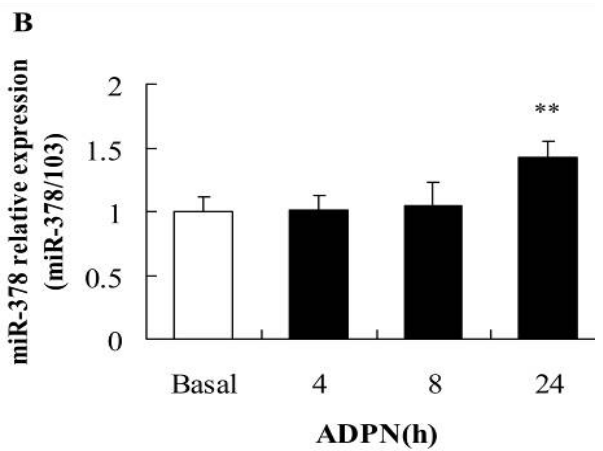

Figure 2: Effect of ADPN on miR-378 expression in mature human adipose tissue cells determined by quantitative RT-PCR relative to that of snRU6 (A) or miR-103 (B). Values are shown as mean \pm SE; ${ }^{*} p<0.05$ relative to control
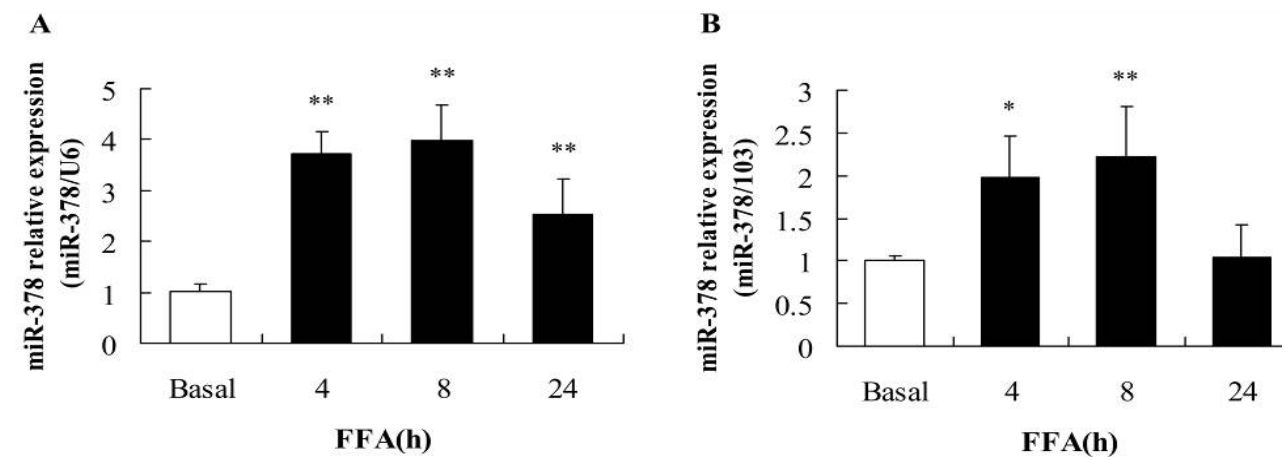

Figure 3: Effect of FFAs on miR-378 expression in mature human adipose tissue cells. The cells were exposed to $1 \mathrm{mmol} / \mathrm{L}$ FFAs for various lengths of time, and the amounts of miR-378 were determined with quantitative RTPCR relative to the level of snRU6 (A) or miR-103 (B). Values are mean $\pm \mathrm{SE}(\mathrm{n}=3) ;{ }^{*} p<0.05,{ }^{* \star} p<0.01$ when compared with values for control
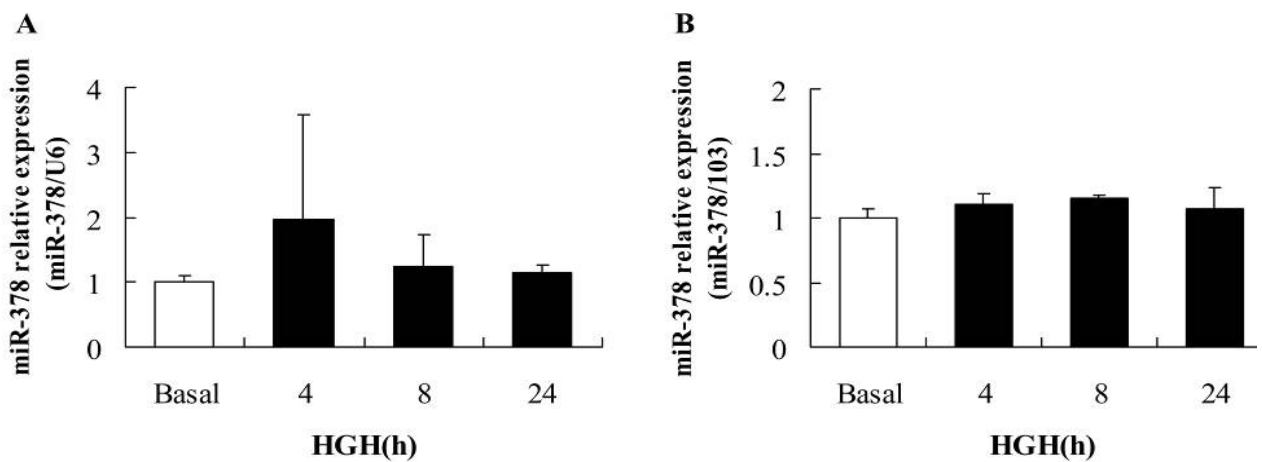

Trop J Pharm Res, January 2018; 17(1): 31 
Figure 4: Effect of $\mathrm{GH}$ on the expression of miR-378 in mature human adipose tissue cells, determined by quantitative RT-PCR relative to snRU6 (A) or miR-103 (B). Values are expressed as mean $\pm S E(n=3)$
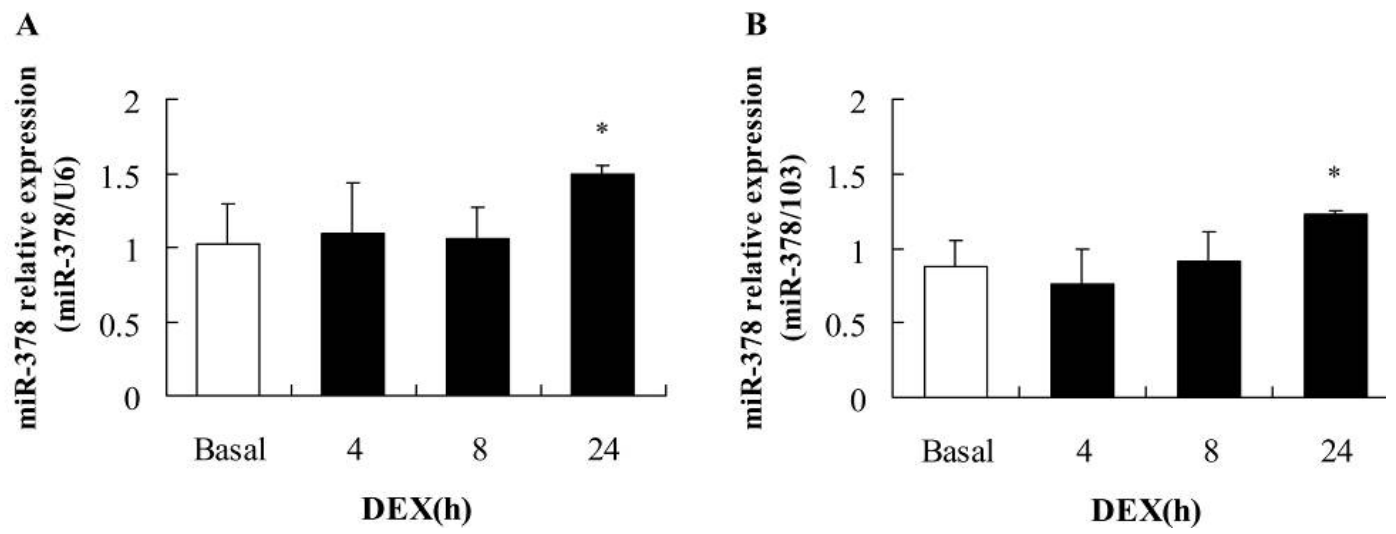

Figure 5: Effect of DEX on miR-378 expression in mature human adipose tissue cells as a function of length of exposure, determined using quantitative RT-PCR relative to snRU6 (A) or miR-103 (B). Values are expressed as mean $\pm \operatorname{SE}(n=3) .{ }^{*} p<0.05$ when compared with control

\section{DISCUSSION}

Existing epidemiological studies have already shown that globally, the incidence of obesity has increased considerably. Obesity is so common in the world today that it is beginning to replace malnutrition as the most significant contributor to ill-health. Obesity is the causative factor for coronary heart disease, hypertension, sleepbreathing disorders and certain forms of cancer. However, type 2 diabetes is by far the most devastating complication of obesity. These two conditions predispose to development of insulin resistance. Obesity refers to excess accumulation of adipose tissue to an extent that negatively affects physical and psychosocial wellness [13]. Adipocytes affect metabolism through the release of FFAs, and secretion of hormones, glycerol, adiponectin, leptin and cytokines. The release of these substances is accentuated by obesity [14].

MiRNAs refer to a group of small and endogenously expressed RNAs that regulate the expression of genes post-transcriptionally. The potential of miRNAs in disease therapy has continued to receive recognition, especially in obesity and type 2 diabetes [15]. In an miRNA expression array study using total RNA extracted from human-derived pre-adipocytes and adipocytes to profile changes in miRNA expression during adipogenesis, the expressions of 70 out of 799 miRNAs assayed were significantly changed between non-induced and induced adipocytes, indicating the importance of miRNAs in adipocyte development [16]. The locus of miR-378 is located in PPARGC1B intron, and it is highly induced during adipogenesis.
In a study, it was shown that mice genetically deficient in miR-378 resisted development of obesity from high-fat diet, but exhibited increased rate of lipid metabolism in the mitochondrion [17]. This indicates the likely involvement of miR-378 in regulating energy balance and metabolic processes in the mitochondria. It has been demonstrated that in the process of adipogenesis, over-expression of miR-378 enhanced triglyceride levels due to increased rate of de novo lipid synthesis [9]. Moreover, Wei Liu et al [18] have shown that hepatic miR-378 is a key regulator of insulin signaling. On the basis of these reports, it can be hypothesized that insulin resistance and obesity may be regulated by energy sources and hormones through interaction with miR-378.

A study has demonstrated that adiponectin levels were decreased in either genetically obese ob/ob or diet-induced obese (high-fat-diet) mouse model [19]. The minor chronic inflammation seen in type 2 diabetes and obesity have also been associated with adipokine dysregulation [20]. Further studies revealed that adiponectin is an anti-inflammatory hormone which increases insulin sensitivity through enhancement of $\beta$ oxidation and suppression of hepatic gluconeogenesis [21]. Thus adiponectin regulates energy metabolism. In the present study, the concentration of adiponectin was low because its levels are decreased in obesity. However, adiponectin treatment (3 $\mathrm{ug} / \mathrm{ml})$ brought about slight increases in expression of miR-378, which reached a peak at $24 \mathrm{~h}$. Based on this result, it is suggested that there exists a feedback regulation mechanism between adiponectin and miR-378. These observations suggest that a reduction in adiponectin increases 
miR-378 expression and contributes to insulin resistance.

One major factor that affects insulin resistance is presence of FFAs. Type 2 diabetes and obesity are associated with high rate of FFAs release, which may be responsible for insulin resistance seen in both diseases [6]. Recently, it was shown that two key ER stress sensors, PERK and IRE$1 \alpha$ were activated by FFAs, and that the use of chemical chaperons to attenuate ER stress reduced the expression of pro-inflammatory cytokines, leading to enhanced insulin sensitivity [22]. The results obtained in this study show significant up-regulation of miR-378 expression 4 h post-FFA exposure, which was sustained to the $8^{\text {th }}$ hour. Thus, miR-378 may be implicated in the pathogenesis of FFAs-associated insulin insensitivity.

Growth hormone $(\mathrm{GH})$ has a pronounced lipolytic effect, particularly on abdominal fat [23]. It stimulates protein synthesis, and enhances fat utilization by increasing oxidation in adipocytes and triglyceride breakdown. In addition, it exerts anti-insulin property by suppressing peripheral tissue uptake of glucose and enhancing hepatic gluconeogenesis [24]. However, the results obtained in this study suggest that $\mathrm{GH}$ is not associated with miR-378-linked insulin insensitivity.

In humans, excess glucocorticoids increase adipose tissue mass, and re-distribute fat between the central and peripheral depots [25]. Glucocorticoids enhance ready availability of energy substrates to cope with energy demands of stress [26]. In humans, prolonged glucocorticoid therapy is linked to central obesity and insulin resistance. The present study has demonstrated that under in vitro conditions, DEX enhanced the expression of miR-378 in mature human adipose tissue cells, suggesting an interaction between glucocorticoid and miR-378 in the pathogenesis of obesity-induced insulin insensitivity.

\section{CONCLUSION}

The findings of this study demonstrate that miR378 expression is influenced by adiponectin, FFAs and dexamethasone, but not by $\mathrm{GH}$. Thus, up-regulation of miR-378 expression may be implicated in the etiology of insulin resistance induced by these obesity-associated factors. Therefore, miR-378 is a potential biomarker for predicting the risk of complications of obesity, especially insulin resistance.

\section{DECLARATIONS}

\section{Acknowledgement}

This project was supported by Science and Technology Development Fund of Nanjing Medical University (no. JMU116).

\section{Conflict of interest}

No conflict of interest is associated with this work.

\section{Contribution of authors}

We declare that this work was done by the authors named in this article and all liabilities pertaining to claims relating to the content of this article will be borne by the authors.

\section{REFERENCES}

1. Padidela $R$, Bennett $K$, Nessa A, Wells J, Aufieri $R$, James $C$, Smith VV, Brain $C$, Eaton $S$, Hussain $K$. Severe resistance to weight gain, lack of stored triglycerides in adipose tissue, hypoglycaemia, and increased energy expenditure: a novel disorder of energy homeostasis. Horm Res Paediatr 2012; 77(4): 261-268.

2. Kassi E PP, Kaltsas G, Chrousos G. Metabolic syndrome: definitions and controversies. BMC Med 2011; 9: 48.

3. Lubrano $C$, Saponara $M$, Barbaro $G$, Specchia $P$, Addessi E, Costantini D, Tenuta M, Di LG, Genovesi G, Donini LM. Relationships between Body Fat Distribution, Epicardial Fat and Obstructive Sleep Apnea in Obese Patients with and without Metabolic Syndrome. Plos ONE 2012; 7(10): e47059-e47059.

4. Spiegelman BM, Flier JS. Obesity and the regulation of energy balance. Cell 2001; 104(4): 531-543.

5. Lau CH, Muniandy S. Novel adiponectin-resistin (AR) and insulin resistance (IRAR) indexes are useful integrated diagnostic biomarkers for insulin resistance, type 2 diabetes and metabolic syndrome: a case control study. Cardiovasc Diabetol 2011; 10(1): 8.

6. Bergman RN, Ader M. Free fatty acids and pathogenesis of type 2 diabetes mellitus. Trends Endocrinol Met Tem 2000; 11(9): 351.

7. Bushati N, Cohen SM. microRNA functions. Annu Rev Cell Dev Biol 2007; 23(23): 175.

8. Ono K. MicroRNA links obesity and impaired glucose metabolism. Cell Res 2011; 21(6): 864-866.

9. Gerin I BG, McCoin CS, Sousa KM, Krishnan V, MacDougald OA. Roles for miRNA-378/378* in adipocyte gene expression and lipogenesis. $J$ Physiol Endocrinol Metab 2010; 299: E198-206.

10. Xu G, Shi C, Ji C, Song G, Chen L, Yang L, Zhao Y, Guo $X$. Expression of microRNA-26b, an obesity-related microRNA, is regulated by free fatty acids, glucose, 
dexamethasone and growth hormone in human adipocytes. Mol Med Rep 2014; 10(1): 223-228.

11. Zhao YP, Zhang CM, Zhu C, Chen XH, Wang JL, Ji CB, Chi $X$, Hong $Q$, Peng $Y Z$, Guo XR. NYGGF4 homologous gene expression in 3T3-L1 adipocytes: regulation by FFA and adipokines. Mol Biol Rep 2010; 37(7): 3291-3296.

12. Schmittgen TD, Livak KJ. Analyzing real-time PCR data by the comparative $C(T)$ method. Nat Protoc 2008; 3(6): 1101-1108.

13. Naser KA, Gruber A, Thomson GA. The emerging pandemic of obesity and diabetes: are we doing enough to prevent a disaster? Int J Clin Pract 2006; 60(9): 10931097.

14. Karpe F, Dickmann JR, Frayn KN. Fatty acids, obesity, and insulin resistance: time for a reevaluation. Diabetes 2011; 60(10): 2441-2449.

15. Ambros $V$. The functions of animal microRNAs. Nature 2004; 431(7006): 350-355.

16. Ortega FJ, Moreno-Navarrete JM, Pardo G, Sabater M, Hummel M, Ferrer A, Rodriguez-Hermosa Jl, Ruiz B, Ricart W, Peral $B$, et al. MiRNA expression profile of human subcutaneous adipose and during adipocyte differentiation. PLoS One 2010; 5(2): e9022.

17. Carrer M, Liu N, Grueter CE, Williams AH, Frisard MI, Hulver MW, Bassel-Duby R, Olson EN. Control of mitochondrial metabolism and systemic energy homeostasis by microRNAs 378 and $378^{*}$. Proc Natl Acad Sci U S A 2012; 109(38): 15330-15335.

18. Gerin I, Bommer GT, McCoin CS, Sousa KM, Krishnan V, MacDougald OA. Roles for miRNA-378/378* in adipocyte gene expression and lipogenesis. Am J Physiol Endocrinol Metab 2010; 299(2): E198-206.

19. Liu W, Cao H, Ye C, Chang C, Lu M, Jing Y, Zhang D, Yao $X$, Duan $Z$, Xia $H$, et al. Hepatic miR-378 targets p110alpha and controls glucose and lipid homeostasis by modulating hepatic insulin signalling. Nat Commun 2014; 5: 5684.
20. Yamauchi T, Kamon J, Waki H, Terauchi Y, Kubota N, Hara K, Mori $Y$, Ide T, Murakami K, TsuboyamaKasaoka $N$, et al. The fat-derived hormone adiponectin reverses insulin resistance associated with both lipoatrophy and obesity. Nat Med 2001; 7(8): 941-946.

21. Lihn AS, Pedersen SB, Richelsen B. Adiponectin: action, regulation and association to insulin sensitivity. Obes Rev 2005; 6(1): 13-21.

22. Kwon H, Pessin JE. Adipokines mediate inflammation and insulin resistance. Front Endocrinol (Lausanne) 2013; 4: 71.

23. Bergman RN, Ader M. Free fatty acids and pathogenesis of type 2 diabetes mellitus. Trends Endocrinol Metab 2000; 11(9): 351-356.

24. Jiao $P$, Ma J, Feng B, Zhang H, Diehl JA, Chin YE, Yan $W, X u H$. FFA-induced adipocyte inflammation and insulin resistance: involvement of $E R$ stress and IKKbeta pathways. Obesity (Silver Spring) 2011; 19(3): 483-491.

25. Gravholt $\mathrm{CH}$, Schmitz $\mathrm{O}$, Simonsen L, Bulow J, Christiansen JS, Moller N. Effects of a physiological GH pulse on interstitial glycerol in abdominal and femoral adipose tissue. Am J Physiol 1999; 277(5 Pt 1): E848854.

26. Lukasova $P$, Vankova $M$, Vcelak J, Vejrazkova $D$, Bradnova O, Stanicka S, Hainer V, Bendlova B. Fat mass and obesity associated gene variants are associated with increased growth hormone levels and affect glucose and lipid metabolism in lean women. Physiol Res 2015; 64 Suppl 2: S177-185.

27. Lonn L, Kvist H, Ernest I, Sjostrom L. Changes in body composition and adipose tissue distribution after treatment of women with Cushing's syndrome. Metabolism 1994; 43(12): 1517-1522.

28. Xu C, He J, Jiang $H, Z u$ L, Zhai W, Pu S, Xu G. Direct effect of glucocorticoids on lipolysis in adipocytes. Mol Endocrinol 2009; 23(8): 1161-1170. 